\title{
The Web Experiment List: A Web service for the recruitment of participants and archiving of Internet-based experiments
}

\author{
ULF-DIETRICH REIPS and RALPH LENGLER \\ University of Zurich, Zurich, Switzerland
}

\begin{abstract}
The Web Experiment List (http://genpsylab-wexlist.unizh.ch/), a free Web-based service for the recruitment of participants in Internet-based experiments, is presented. The Web Experiment List also serves as a searchable archive for the research community. It lists more than 250 links to and descriptions of current and past Web experiments. Searches can be conducted by area of research, language, type of study, date, and status (active vs. archived). Data from log file analyses reveal an increasing use of the Web Experiment List and provide a picture of the distribution of the use of the Web experiment method across disciplines. On a general theoretical note, Web services are discussed as a viable software alternative to the traditional program format.
\end{abstract}

The number of experiments conducted via the WorldWide Web appears to have grown exponentially since 1995, when psychologists began to take advantage of the new standard for HTML that allows for convenient data collection (Musch \& Reips, 2000). Internet-based research has become a new topic in psychology, and many researchers are looking for services that support this type of research.

In this article, we present the Web Experiment List (http://genpsylab-wexlist.unizh.ch/), a Web-based service for the recruitment of participants in Internet-based experiments. The Web Experiment List is also a searchable archive for the research community. It lists more than 250 links to and descriptions of current and past Web experiments. Figure 1 shows the list's main page.

\section{Two Types of Software: Programs and Web Services}

A number of tools have been developed for Internetbased experimenting that form a general framework of reference for the methodology. These tools can be grouped into two general classes of "software": programs and Web services. ${ }^{1}$ Programs follow the traditional format. They need to be installed on a computer and run locally. The working of the program depends on the computer's configuration, which may vary considerably over time (as other software is installed) and from user to user. Different types of operating systems may not allow a user to install the software at all. Upgrades and updates may be

The article is based on a presentation given at the "Tools for InternetBased Research" symposium at the 34th Annual Meeting of the Society for Computers in Psychology, Minneapolis, November 18, 2004. Correspondence concerning this article should be addressed to U.-D. Reips, Psychologisches Institut, Universität Zürich, Rämistr. 62, 8001 Zurich, Switzerland (e-mail: u.reips@psychologie.unizh.ch). necessary. However, the user is in control of the service and independent of a connection to the Internet. An example of a tool for Internet-based experimenting (in this case for Web-based decision-making experiments) of the program type is WebDIP (Schulte-Mecklenbeck \& Neun, 2005).

Web services, on the other hand, run on a server that is connected to the Internet. Users access it via a Web browser and can use it only while they are connected to the Internet. Because the functionality of Web browsers is less dependent on the operating system (sometimes they are even referred to as being platform independent), all who access a Web service are likely to see and experience almost the same interface (but see, e.g., Dillman \& Bowker, 2001, for browser-related problems in Internetbased research). Web services spare the user from upgrading and updating, since this is done by the Web service administrators at the server. Nothing is installed on the user's computer, saving space and time.

The Web Experiment List is such a Web service, because the highly frequent interactive exchange of many people in different roles (researchers, participants, students, historians, administrators) with the Web site could not possibly be organized via the program concept. The Web Experiment List is even part of a whole set of several general Web services for Web-based experimentation that were developed to complement each other. These are: WEXTOR ${ }^{2}$ (Reips \& Neuhaus, 2002), the Web Experiment List, the Web Experimental Psychology Lab (Reips, 2001), and Scientific LogAnalyzer (Reips \& Stieger, 2004). This set of tools covers every step in the Internet-based research process: developing a Web experiment, recruiting participants, and analyzing the data.

\section{Recruiting Internet Participants}

Some of the best places for recruitment are institutionalized Web sites for Internet-based experimenting, 


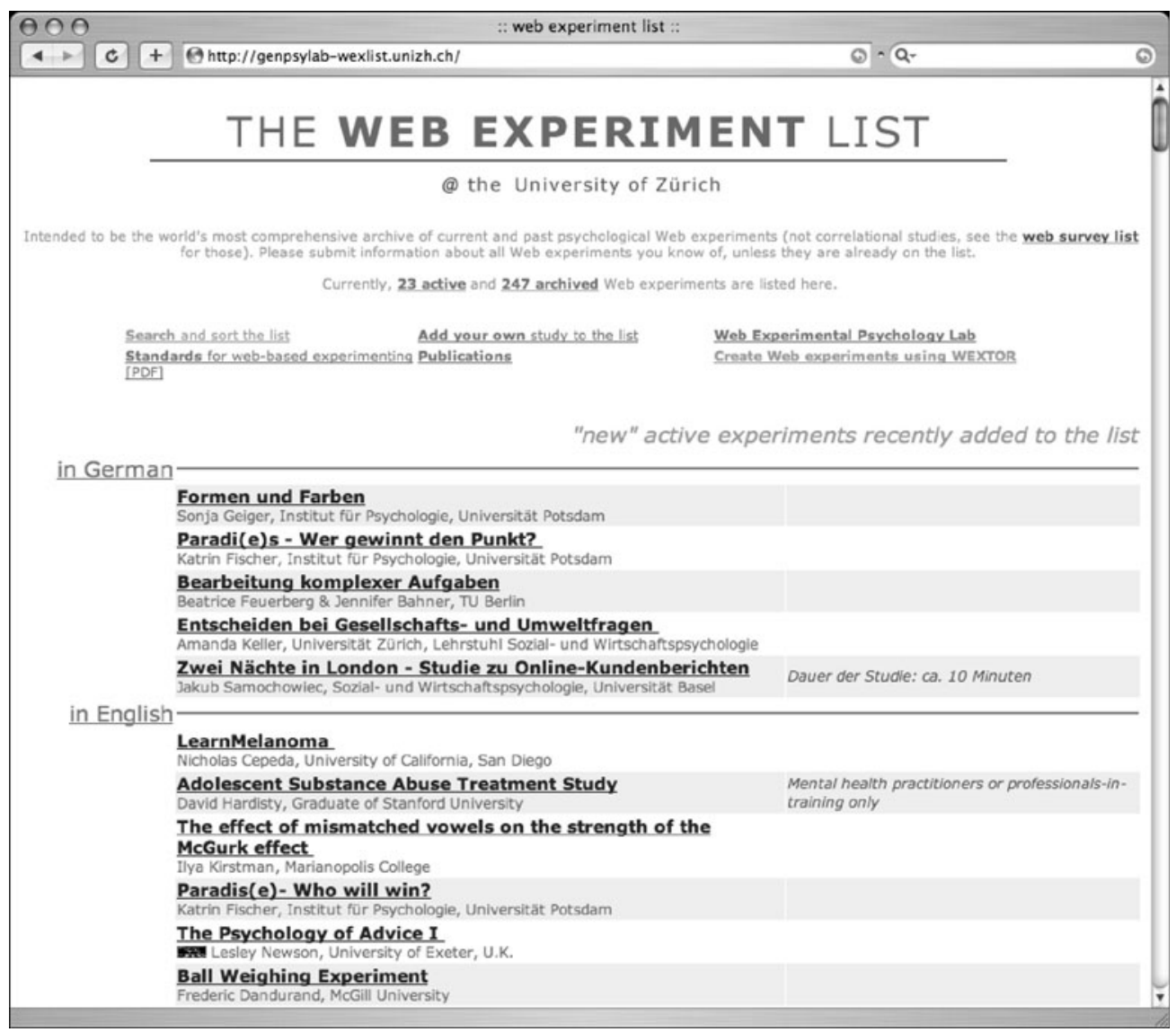

Figure 1. Main page of the Web Experiment List Web site, with lists of new, older active, and archived Web experiments in English and German. The page also contains links to the entry form for one's own study and to other information about Internet-based experimenting.

such as (in addition to the the Web Experiment List) the Web Experimental Psychology Lab and the Psychological Research on the Net list by John Krantz, who published one of the first Web experiments (Krantz, Ballard, $\&$ Scher, 1997). Every month, these Web sites are visited by thousands of potential participants (Reips, 2001). A link on a Web experiment site may also serve as an archive, as an example for future studies, as a resource for students of psychological research, and as a reference in publications.

Some of the links to these and other sites on the Web that contain large collections of psychological studies that are currently in progress are Psychological Research on the Net (by John Krantz), http://psych.hanover.edu/ research/exponnet.html; Web Experimental Psychology Lab (by Ulf-Dietrich Reips), http://www.psychologie. unizh.ch/sowi/Ulf/Lab/WebExpPsyLab.html; Decision Research Center (by Michael Birnbaum), http://psych. fullerton.edu/mbirnbaum/decisions/thanks.htm; Lab-United-International Online-Research (by Anja Berger and Mirko Wendland), http://www.lab-united. com/; and Social Psychology Network (by Scott Plous), http://www. socialpsychology.org/expts.htm.
People coming to a study via one of these Web research sites are true volunteers who have already decided that they want to take part in one or more psychology studies. Consequently, the concerns one might have with respect to students who are participating only to fulfill an assignment are relieved with this source of participants.

\section{How to Link an Experiment to the Web Experiment List}

Near the top of the main page at http://genpsylabwexlist.unizh.ch/, there is a link called Add your own study to the list that opens a form. Figure 2 shows this entry form, which an experimenter must fill out to put a Web experiment on the Web Experiment List.

The entry form contains a number of fields and options. For example, entries about the author's name, the institution, the e-mail of the author, the title and a brief description of the experiment have to be provided in the language chosen in the respective menu (currently, the descriptions can be in English and German). The user is asked to provide the URL, the date up to which the study is to be marked as active, and any important remarksfor example, whether the study can only be accessed 


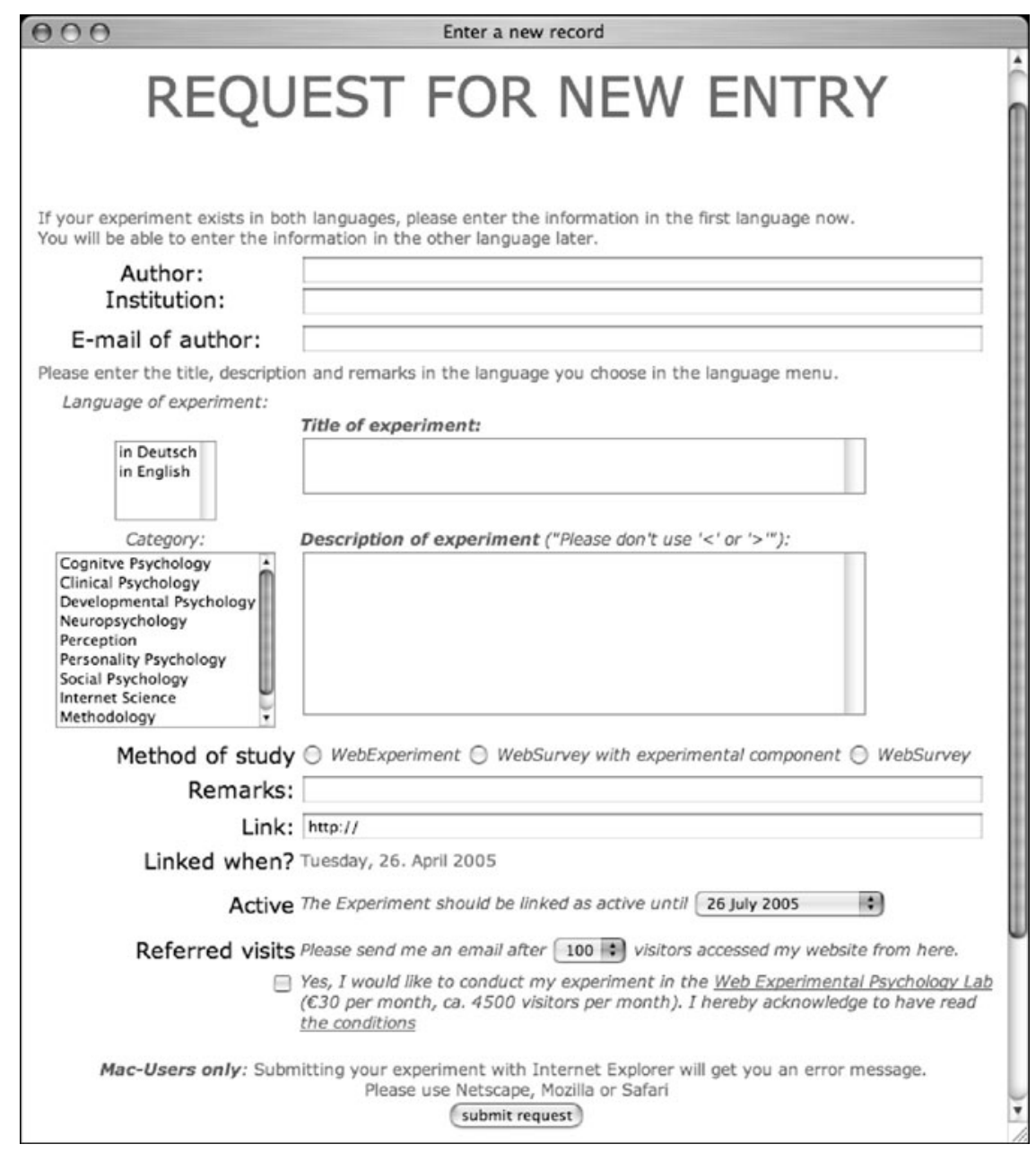

Figure 2. The request for new entry form, with fields for information about the Web study and configurable options.

with a certain plug-in or Web browser. Because the form is shared with a second Web site (the Web Survey List) the method of study also needs to be specified: Web experiment, Web survey with experimental component, or Web survey. From a drop-down menu, the user can choose the number of referred visits (visitors accessing the study via the Web Experiment List) before an automatically generated e-mail will be sent back to him or her. In addition, the user is offered the choice of having the Web experiment also linked to the Web Experimental Psychology Lab (Reips, 2001), which generates much higher visitor traffic but has stricter conditions of ratification of linked Web experiments.

After clicking the "Submit" button, the user is presented with a confirmation page that summarizes the entered information in the same format as that in which it will be displayed on the study's page in the Web Experiment List (see Figure 3). This Web page contains the following information and options: a statement as to whether everything has been inserted successfully; whether the study will be displayed as being currently active or archived; the area of research chosen (e.g., "Cognitive Psychology" or "Internet Science"); the submission date; the method of the study; the author, the author affiliation, the title of the study, and a brief description of the experiment; special remarks, such as whether the study works with all Web browsers; a link that returns the user to the previous page if a change of entries is desired; and a link that allows the user to submit the experiment in the other language (names and other languageindependent entries need not be retyped). The user can also close the window or go back to the Web Experiment List's main page.

After a Web experiment has been submitted, an automatically generated e-mail is sent to the user that confirms the submission of the entry. A second e-mail is sent to the list manager, informing him of the new entry. The list manager then (roughly) evaluates the experiment for obvious usability problems and in light of guidelines for Internet-based experimenting (e.g., Reips, 2002). If nec- 


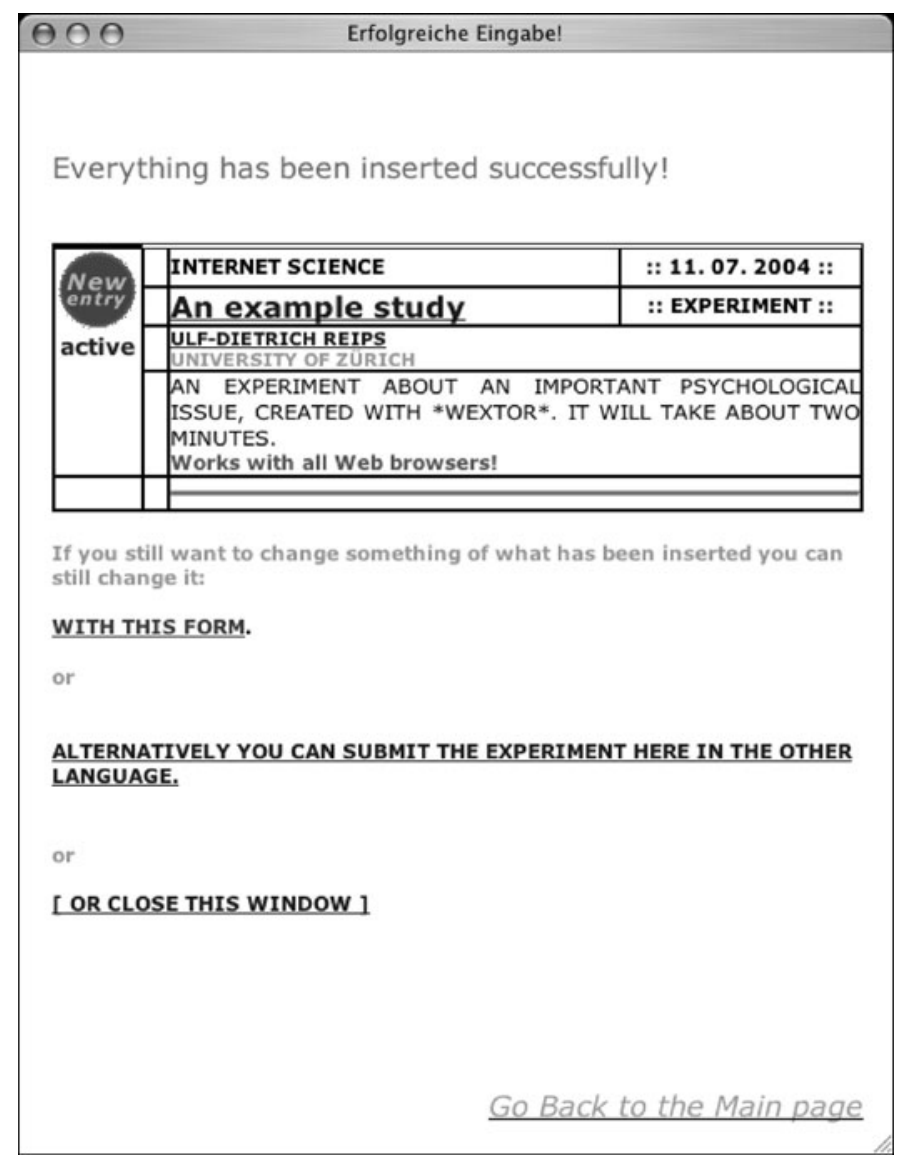

Figure 3. The feedback screen that is shown after a study is entered. The study description is displayed in the very same format as would be seen after one clicks a study link on the main page.

essary, he requests additional information or points out incompatibilities and ethical or methodological issues, before linking the study to the publicly accessible list. This routine check and the listing is free of charge.

\section{Features and Options}

The Web Experiment List can be collapsed or shown in full. It shows recently added Web experiments separately from older ones, and it shows for which experiments data are being actively collected.

One of the more important features is the search and sort option in the Web Experiment List. Figure 4 shows how an array of drop-down menu and radio buttons allows for combined searches. Using this option, it is easy to, let's say, find all new and active social psychology experiments that are in English.

On a critical note, one might argue that a list or portal format may not be ideal for all user types (researchers in search of participants, participants in search of Webbased studies, teachers and students on a quest for educational material about psychological experiments, members of the scientific community in search of an archive, etc.). However, with the search feature, the Web Experiment List already contains a second way of finding Web experiments within the site. Also, to date, no other ways of making a large collection of Web experiments accessible to the public have been successfully launched on the Internet. Empirically, like the other lists mentioned earlier, the Web Experiment List stands as a well-used Web site and gathers some interesting statistics regarding the types of Web experiments conducted and accessed, as will be shown in the next section.

\section{Usage Data and Descriptives}

Two thirds of submitted Web experiments are in English only, about $27 \%$ are in German only, and $6 \%$ are conducted in both languages. The ratio of click-throughs to the German version is about four fifth of the participants clicking through to the English version of the same studies. Currently, about $10 \%$ of the experiments are active; all others are archived. The most frequently accessed experiment among the more than 250 listed Web experiments was accessed more than 1,200 times (about 750 times in the German version and about 450 times in the 


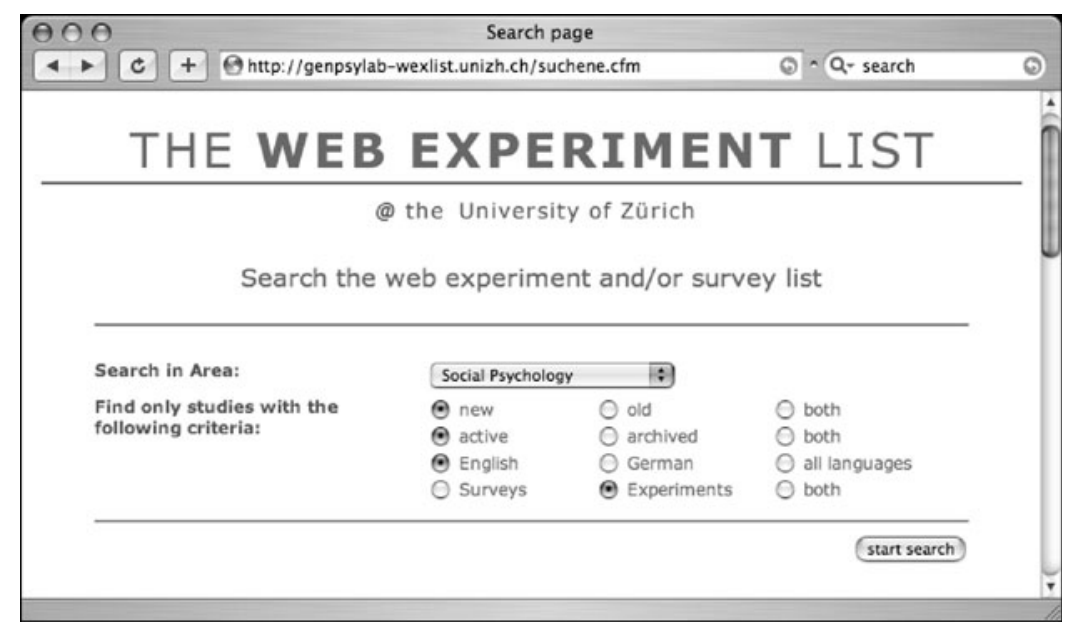

Figure 4. All listed studies are searchable by category via the interface that is displayed in this figure.

English version). About 100 Web experiments are in cognitive psychology, about 90 in social psychology, about 25 in perception, and about 10 each in Internet science, personality, and clinical psychology, with very few in developmental psychology and neuropsychology. New studies are currently being added at a rate of about one to three per week.

Visits to the Web site have increased from about 35 to about 40 per day during the last 7 -month period we evaluated, excluding visits by search engine spiders and robots. Top-level domains that clearly indicate 1 of 64 countries of originating access (not .net or .com etc.) reveal that most visitors came from Switzerland, Germany, the United States, the United Kingdom, and Japan. There were about three visits a day in which the Web Experiment List was found via a search engine. Of these, $80 \%$ came via Google, $10 \%$ via Yahoo, and $10 \%$ via other search engines. Top search terms were "experiment" (and word derivations), "psychology," "list," "web," and "survey." The list of search phrases also shows that the Web Experiment List was often found when people searched for the name of a particular researcher.

An analysis of paths taken through the Web site shows that many visitors first clicked on the link at the bottom of the initially short page to expand the view to the full list. Length of visits was between $15 \mathrm{sec}$ and $14 \mathrm{~min}$ for most visitors, with an average of a little more than $3.5 \mathrm{~min}$. Making a new entry to the Web Experiment List takes about 3:20 min, on average. Reading the description of one of the Web experiments takes about 1:10 min on average, and the average view time for the archive is about 1:50 min. Using the search engine takes about half a minute, on average.

\section{Discussion and Outlook}

A Web service was presented that is designed to be of help to Web researchers who wish to freely recruit participants on the Internet for their Internet-based experi- ments. With its vast archive, the service offers examples of completed studies for those who seek to learnnamely, teachers and students of psychology. Readers of empirical reports that are based on Internet-based experiments may visit to get detailed "participant experiences." And last but not least, the Web Experiment List serves people from the larger population who wish to find and be part of the exciting process of research, who otherwise might never have had the opportunity to participate in a study.

Future developments of the Web Experiment List will include the buildup of a participant pool that will be available as an additional source of participants to those researchers who link their Web experiments to the list. We also contemplate adding more features to the search page - for example, searching by popularity or even full text search. Because some Web experiments do not remain on line for display after data collection has finished and, therefore, the archiving function of the list is continuously challenged, a feature may be added that takes a "snapshot" of the experiments at the time of submission.

Recently, we set up a sister Web site for Web-based surveys, the Web Survey List. Although there was an obvious need for such a list of surveys, given the higher base rate of this study type on the Internet and the frequent requests for listing we received, it is still too early to assess whether this new list will be a success. We certainly hope that both the Web Survey List and the Web Experiment List will be or continue to be of help to the community of researchers who have begun to use the Internet for the study of human behavior.

\section{REFERENCES}

Birnbaum, M. H., \& ReIPs, U.-D. (2005). Behavioral research and data collection via the Internet. In R. W. Proctor \& K.-P. L. Vu (Eds.), The handbook of human factors in Web design (pp. 471-492). Mahwah, NJ: Erlbaum. 
Dillman, D. A., \& Bowker, D. K. (2001). The Web questionnaire challenge to survey methodologists. In U.-D. Reips \& M. Bosnjak (Eds.), Dimensions of Internet science (pp. 159-178). Lengerich, Germany: Pabst.

Krantz, J. H., Ballard, J., \& Scher, J. (1997). Comparing the results of laboratory and World-Wide Web samples on the determinants of female attractiveness. Behavior Research Methods, Instruments, \& Computers, 29, 264-269.

Musch, J., \& REIPS, U.-D. (2000). A brief history of Web experimenting. In M. H. Birnbaum (Eds.), Psychological experiments on the Internet (pp. 61-87). San Diego: Academic Press.

ReIPs, U.-D. (2001). The Web Experimental Psychology Lab: Five years of data collection on the Internet. Behavior Research Methods, Instruments, \& Computers, 33, 201-211.

REIPS, U.-D. (2002). Standards for Internet-based experimenting. Experimental Psychology, 49, 243-256.

ReIPS, U.-D., \& Neuhaus, C. (2002). WEXTOR: A Web-based tool for generating and visualizing experimental designs and procedures. $\mathrm{Be}$ havior Research Methods, Instruments, \& Computers, 34, 234-240.

ReIPS, U.-D., \& Stieger, S. (2004). Scientific LogAnalyzer: A Webbased tool for analyses of server log files in psychological research. Behavior Research Methods, Instruments, \& Computers, 36, 304-311.
SchmidT, W. C. (2000). The server-side of psychology Web experiments. In M. H. Birnbaum (Ed.), Psychological experiments on the Internet (pp. 285-310). San Diego: Academic Press.

Schulte-Mecklenbeck, M., \& Neun, M. (2005). WebDiP - A tool for information search experiments on the WWW. Behavior Research Methods, 37, 293-300.

\section{NOTES}

1. Despite a certain similarity, the distinction between programs and Web services differs from another important one in Internet-based research: client-side versus server-side (Birnbaum \& Reips, 2005; Reips, 2002; Schmidt, 2000). Client-side and server-side processes are directed by a central agent (e.g., a Web service); programs and Web services are central agents.

2. http://psych-wextor.unizh.ch/wextor/.

(Manuscript received January 1, 2005; revision accepted for publication May 20, 2005.) 